\title{
Study on Teaching Reform of Macro-Finance Curriculum: Public Finance, Financial Economics and International Finance
}

\author{
Ping $\mathrm{Li}^{1}{ }^{*}$, De'an Gan², Shiyan $\mathrm{Li}^{1}$ \\ ${ }^{1}$ School of Economics and Management, Wuchang Shouyi University, Wuhan, China \\ ${ }^{2}$ Gengdan Institute of Beijing University of Technology, Beijing, China \\ Email: "liping870415@163.com
}

Received 24 August 2015; accepted 27 November 2015; published 30 November 2015

Copyright (C) 2015 by authors and Scientific Research Publishing Inc.

This work is licensed under the Creative Commons Attribution International License (CC BY). http://creativecommons. org/licenses/by/4.0/

(c) ()

\section{Abstract}

Financial discipline has two branches, macro-finance and micro-finance. Compared with the micro-finance, macro-finance theory is featured by stronger comprehensiveness, which increases teaching difficulties. With the development of macro-economic, financial theories continuously innovate and students' knowledge structure plays a more important role in teaching. By integrating the courses, a knowledge chain can be formed, which makes it easier for students to solve financial problems. Meanwhile, this paper proposes a series of methods to improve the teaching effect, including inheritance and innovation of traditional lecture, case analysis assisted by videos, spot investigation, positive scene simulation and knowledge structure graph. In addition, strengthening review lessons and the application of MOOC is advisably.

\section{Keywords}

Integration, Inheritance and Innovation, Positive Scene Simulation, Problem-Oriented Method

\section{Introduction}

Financial discipline has two branches, macro-finance and micro-finance (Jiang, 1955a). An independent course can't solve problems of financial industry, especially in the field of macro-finance. Students may learn some lonely facts, concepts and principles, but they don't know how to use them. When meeting problems, they may feel doubtfully. Many researches focus on the teaching reform of an independent course of finance. However, research on curriculum system is less. Public finance, financial economics and international finance which be-

${ }^{*}$ Corresponding author.

How to cite this paper: Li, P., Gan, D. A., \& Li, S. Y. (2015). Study on Teaching Reform of Macro-Finance Curriculum: Public Finance, Financial Economics and International Finance. Creative Education, 6, 2227-2231.

http://dx.doi.org/10.4236/ce.2015.620229 
long to macro-finance, cover a large number of knowledge points and provide a broad outline of macro-finance (Jiang, 1955b). This paper, taking the three courses for example, studies the teaching reform of macro-finance curriculum, including the integration of the courses and the reform of teaching methods. The integration of the courses focuses on the teaching sequence and the methods of thinking in terms of the overall picture. The reform of teaching methods consists of inheritance and innovation of traditional lecture method, case analysis, spot investigation, positive scene simulation, knowledge structure graph and review lessons.

\section{Problems}

\subsection{High Requirements for Students' Knowledge Structure and Theoretical Basis}

Macro-finance theories are featured by strong comprehensiveness. Students are required to have a thorough grounding. Macro and micro economics, political economy, accounting principle, advanced mathematics, probability theory and English are necessary (Li, 2014). Some students don't have a thorough grounding, it will bring difficulties to their future professional courses study. For example, substantial numbers of students achieve good results in all subjects but mathematics in Chinese ordinary tertiary institutions. This will be an obstacle for the teaching of financial theories and models, which retards students' future learning.

\subsection{Difficulties in Forming Knowledge Chain}

Macro-finance curriculum covers a wide range of contents, which have close correlations. Neglecting the connection with other courses is the chief problem existing in macro-finance teaching currently. For instance, disequilibrium between money supply and money demand result in inflation and monetary policy solution is effect. But when meeting deflation, monetary policy may play a less prominent part in the solution. Fiscal Policy in public finance and internal and external equilibrium analysis in international finance are needed. Another example, understanding the theory of money creation, students should have ability of mathematical reasoning. This will further hinder their understanding of Money Supply Model.

\subsection{Rapidly Update of Knowledge}

With the changing of macro-economic environment and the development of information technology, financial theory and the operation mode of financial business continuously innovate. Furthermore, it is difficult for students to decide whether the former or the current theory is available when solving a financial matter. Therefore, teaching contents should be adjusted correspondingly.

\subsection{Traditional Teaching Methods Cannot Satisfy the Needs}

Learning Pyramid (Zhao, 2006) Model propounded by National Training Laboratory, Maine indicated that retention rate of learning is inversely proportional to the usage rate of the teaching methods listed in the learning pyramid, as shown in Figure 1. Traditional teaching methods cannot appropriate to demand nowadays, especially in the teaching of macro-finance curriculum.

\section{Integration of the Courses}

\subsection{Thinking in Terms of the Overall Picture}

As a Chinese idiomatic phrase goes, to see the minute details but miss the major issue. Using a single theory to solve an economic problem may draw diametrically opposite conclusions. Thinking in terms of the overall picture is necessarily. Take the courses of public finance, financial economics and international finance for example, a four-sector economical operation model can be constructed, as shown in Figure 2. The commodity circulation chain and the currency circulation chain are the basis of it. There are three main outflow factors in the modle, including savings, fiscal revenue and import. However, investment, fiscal expenditure and export are the three main inflow factors of the system. When the sum of the three main outflow factors equals to the sum of the three main inflow factors, economic recover equilibrium. This means knowledge in the three courses must be used synthetically to solving economic problems. 


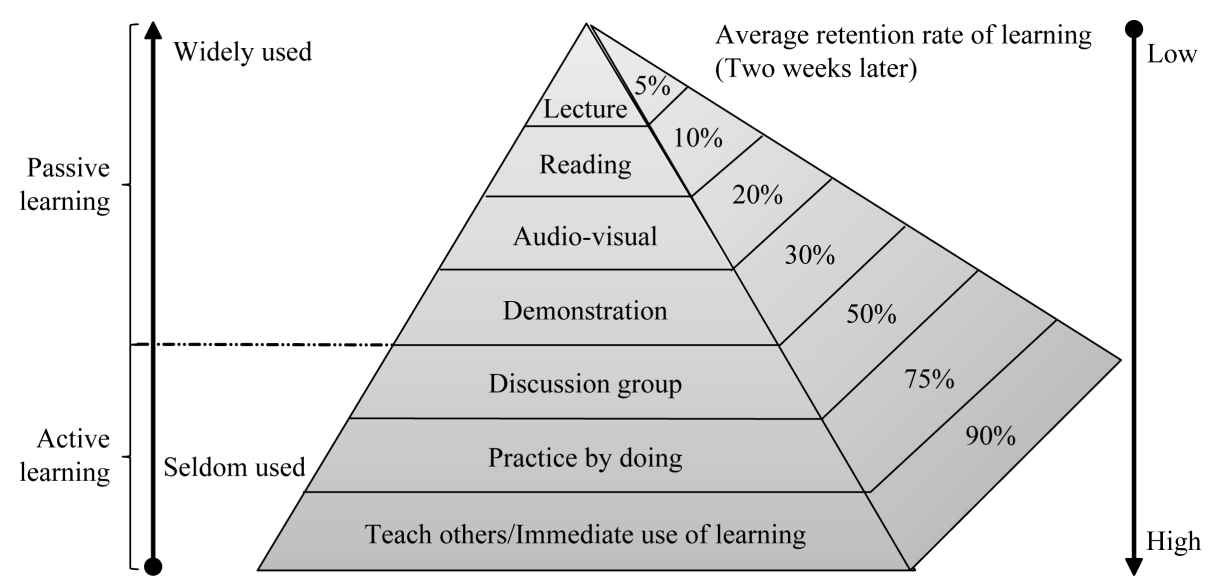

Figure 1. Learning pyramid and the relevance.

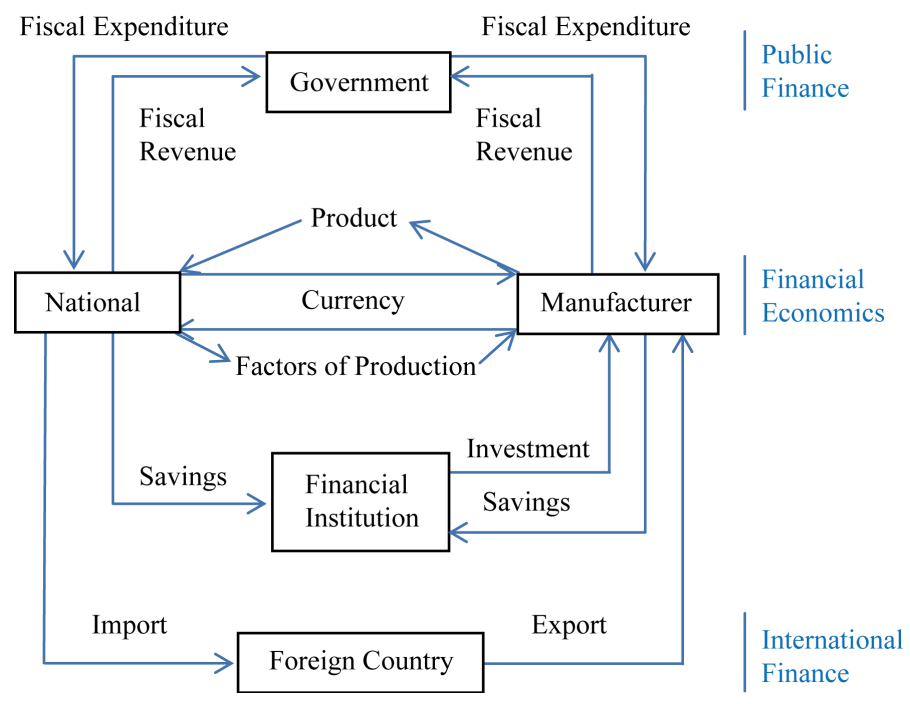

Figure 2. Economical operation model.

\subsection{Unification of Logic and History}

Teaching off a blackboard is boring, and undoubtedly turns people off. So, the logical of teaching should adhere to the evolution of macro-finance. Courses can be presented in chronological order or logical order, which lead students to become an explorer and to solve problems by themselves. During this process, students can easily understand and remember what they have learned. Moreover, the connection between knowledge points can be strengthened, which lead to real understanding.

\section{Reform of Teaching Methods}

\subsection{Inheritance and Innovation of Traditional Lecture Method}

With the booming of China's financial industry in recent years, finance specialty is favored by more students and their parents. The stability of student source in finance requires more teaching resources. Traditional lecture method can easily complete the teaching of class with a lot of students. Thus, it becomes the mainstream pattern of teaching. With the continuous popularization of information technology, the use of multimedia teaching equipment provides conditions for the curriculum reform. A qualified teacher should fully integrate these teaching resources and optimize the teaching effect. Improve the level of courseware is particularly important. Elegant animation design and practice can clearly display the boring theory deduction or business steps. The audio and visual method may help students' memory and understanding. Therefore, a simple flash and a micro video 
can help teachers to show their daily accumulation corresponding with teaching content vividly.

\subsection{Use Videos to Assist Case Analysis}

Development of financial industry has attracted a lot of attention in the media. Financial talk show like a hundred flowers in bloom, such as Larry. Lang and FQ deciphered. Most of these programs invited well-known economists and scholars to discussed recent financial issues. Teacher can choose some classical interview related to the course, using them as an import case or a case for practice. Students will be interested in these and they can get some professional knowledge easily during these programs. It is worth noting that show the interview directly to students is undesirable, teachers must design questions which can guide and inspire them to analyze and discuss the issue, applying theories they have just learned (Dai, 2010).

Using the video to assist case analysis, please note the following points. Firstly, the video should be concise, up-to-date, closely related to the teaching content, and with an appropriate difficulty, this method can't exceed five times per course, or visual fatigue may impact teaching effect. Secondly, teaching content will be discussed with the problem-oriented method, every detail should be designed well before the lecture, such as, purpose of watching the video, questions for discussion and the determining of tutorial groups. Heuristic education is a kind of teaching thought, should run through entire teaching course. Thirdly, brainstorm, which will not bound students' thinking, is a good method. A lot of unexpected results will occur. Finally, wrap-up discussion promptly, which can help incentive next time's discussion.

\subsection{Spot Investigation}

Many knowledge points in macro-finance curriculum belongs to the category of applied economics, Spot investigation is direct and practical, which can help absorb the theories. For instance, if students learn the validity of fiscal and monetary policy only by the lecture teaching, they may feel empty and cannot apply the policy. Another example, one cannot master the securities trading procedures or foreign exchanges procedures only by spot investigation. Teachers can encourage students to go to financial institutions or financial regulators for business, or consulting business. After such spot investigation, students will raise many questions. Therefore, teachers must arrange a time to resolve their problems and let them share experiences.

\subsection{Positive Scene Simulation}

Students may have no opportunity to cognize some financial business or financial phenomenon by spot investigation. For example, student can't satisfy the condition of a business, or a financial phenomenon is not suitable for local conditions nowadays. Universities can construct simulation laboratories to provide software and hardware support. In addition, financial scripts are interesting and effectiveness, the scripts should be played by students in class. Using this method, students may easily master the knowledge.

\subsection{Construction and Application of Knowledge Structure Graph}

Macro-finance curriculum features an extensive knowledge points, many of these are interrelated. Using a single theory to illustrate economic phenomena may lead to unilateral, even opposite results. The conventional knowledge structure graph can only connect knowledge points of one course. Therefore, teacher should not only construct a single knowledge structure graph of one course but mark out the differentiation and relation between courses (Zhang, 2015). That means, completing an extended knowledge structure graph. An economic phenomena is complex, different given conditions may lead to different results. Students should have the ability to make a distinction and analyze it, then producing a brilliant solution.

\subsection{Strengthening Review Lessons and MOOC}

Fudan University's MOOC survey shows that even the first class students in China are unable to review what they have learned consciously, majority of students review only before examination. If teachers let students review only by themselves, subsequent courses will become difficult. However, if review lesson is only a lecture, students cannot participate in well and the effect may not be satisfactory. The following methods for review can be adopted. Flipped classroom, supported by information technology, provides a new way for students to review 
and prepare knowledge after class. Learners cannot only go to the online class, but also discuss with teachers. Resources are open and shared on the internet, students can learn anytime and anywhere. Besides, problem-oriented method can also be used in review lessons, the main points have been mentioned above. At last, by strengthening review lessons in a positive way, the effect of learning must be improved. That is, students are required to review or to resolve some problems by themselves after class and to retell the key points at the beginning of next class. PPT is necessary for the presentation, teacher can check it and make a supplement. Both of them are marked as a part of appraisals.

\section{Conclusion}

The methods presented in this paper have been implemented in educational practice. By integrating the courses, a knowledge chain can be formed, which makes it easier for students to solve financial problems. Meanwhile, by using the novel methods including case analysis assisted by videos, spot investigation, positive scene simulation and knowledge structure graph, the teaching effect has been greatly improved. However, there are also some imperfections in the study of the application of MOOC, The author will focus on it in the following research.

\section{Acknowledgements}

This work is supported by "Twelfth Five-Year Plan” key project of Wuhan Education and Science [grant No. 2013A041], the top-quality courses construction project of Wuchang Shouyi University [grant No. 2012J07] and the top-quality courses construction project of Department of Finance and Economics of Wuchang Shouyi University [Public Finance].

The authors also gratefully acknowledge helpful comments and suggestions of the reviewers, who have improved the presentation.

\section{References}

Dai, X. (2010). Study on the Reform of the Current Financial Report System of China. International Journal of Economics and Finance, 1, 12-21. http://dx.doi.org/10.5539/ijef.v2n1p115

Jiang, B. (1995a). On the Framework of the Academic Discipline of International Finance. Fudan Journal (Social Sciences), 5, 67-76.

Jiang, B. (1995b). Macroeconomic Regulation and Policy under the Open Economy, Social Science in China, 6, 53-61.

Li, S. (2014). Reflections on the Reform in Teaching Content and Teaching Method of Finance of Independent Institute. Logistics Engineering and Management, 9, 54-57.

Zhang, Q. (2015). The Consideration of Large Case Teaching Method Used in International Finance Courses. Research of Finance and Education, 2, 75-78.

Zhao, H. (2006). Application of Learning Pyramid Mode in "Surgical Nursing Science” Teaching. Chinese Nursing Research, 5, 1403-1404. 